\title{
Engineering and Computational Mechanics: Referees 2019
}

The following is a list of referees who have reviewed papers for engineering and computational mechanics between 1 January and 31 December 2019. The Institution of Civil Engineers is very grateful for their assistance.

We are continually looking for suitable reviewers for papers submitted to Engineering and Computational Mechanics. Papers published in the Proceedings of the ICE must be submitted to at least two independent referees to judge accuracy, style, impact, importance and interest.

\author{
Mohammad hosein Abbasi \\ Layth Al-Rukaibawi \\ Waled Alnaas \\ Ahmet Can Altunisik \\ Danial Amini Baghbadorani \\ Hazi Azamathulla \\ Terry Bennett \\ Basuraj Bhowmik \\ Alistair Borthwick \\ Keith Carter \\ Alan Chandler \\ Malcolm Cook \\ Ilaria Crema
}

If you are interested in reviewing articles on any topic related to engineering and computational mechanics, please submit your name, qualifications or $\mathrm{CV}$, and areas of expertise. We are in need of individuals who will agree to review papers in a timely fashion (within 3 to 4 weeks of receipt) and provide confidential feedback to the Editorial Advisory Panel concerning the quality of the paper and any suggested revisions that would be appropriate.

If you are such a person, please contact Jaskarn Rai

(tel.: +44 (0)207 665 2453; e-mail: jaskarn.rai@ice.org.uk) for more information on the referee process.

Chennakesava Kadapa
Rocco Lagioia
Gregory Lane-Serff
Andrew Liew
lain MacLeod
Carmelo Majorana
Chinthaka Mallikarachchi
Michele Mossa
Rosaria Musumeci
Erkan Oterkus
Vikram Pakrashi
Sam Rigby
Jose Santos

Yahya Sheikhnejad

Fangbao Tian

Jon Trevelyan

Savvas Triantafyllou

Andrzej Truty

Yong Wang

Xiao Xiao

Jinquan $\mathrm{xU}$

Jisheng Zhang

Dr Ou Zhao 